\title{
Angiogenesis in cancer
}

\author{
Naoyo Nishida ${ }^{1,2}$ \\ Hirohisa Yano' \\ Takashi Nishida ${ }^{3}$ \\ Toshiharu Kamura ${ }^{2}$ \\ Masamichi Kojiro' \\ Departments of 'Pathology and \\ 2Obstetrics and Gynecology and \\ Research Center of Innovative \\ Cancer Therapy of the 2I Century \\ COE Program for Medical Science, \\ Kurume University School of \\ Medicine, Fukuoka, Japan; ${ }^{3} \mathrm{Hita}$ \\ Saiseikai Hospital, Oita, Japan
}

Correspondence: Naoyo Nishida Department of Pathology, Kurume University School of Medicine 67, Asahimachi, Kurume, Fukuoka 830-00I I, Japan Tel +8I 9423 I 7546

Fax +8I 942320905

Email naoji@med.kurume-u.ac.jp

\begin{abstract}
New growth in the vascular network is important since the proliferation, as well as metastatic spread, of cancer cells depends on an adequate supply of oxygen and nutrients and the removal of waste products. New blood and lymphatic vessels form through processes called angiogenesis and lymphangiogenesis, respectively. Angiogenesis is regulated by both activator and inhibitor molecules. More than a dozen different proteins have been identified as angiogenic activators and inhibitors. Levels of expression of angiogenic factors reflect the aggressiveness of tumor cells. The discovery of angiogenic inhibitors should help to reduce both morbidity and mortality from carcinomas. Thousands of patients have received antiangiogenic therapy to date. Despite their theoretical efficacy, antiangiogeic treatments have not proved beneficial in terms of long-term survival. There is an urgent need for a new comprehensive treatment strategy combining antiangiogenic agents with conventional cytoreductive treatments in the control of cancer.
\end{abstract}

Keywords: angiogenesis, immunohistochemistry, prognosis

\section{Introduction}

Cancer has the ability to spread to adjacent or distant organs, which makes it life threatening. Tumor cells can penetrate blood or lymphatic vessels, circulate through the intravascular stream, and then proliferate at another site: metastasis (Folkman 1971). For the metastatic spread of cancer tissue, growth of the vascular network is important. The processes whereby new blood and lymphatic vessels form are called angiogenesis and lymphangiogenesis, respectively. Both have an essential role in the formation of a new vascular network to supply nutrients, oxygen and immune cells, and also to remove waste products (Folkman 1971). Angiogenic and lymphangiogenic factors are increasingly receiving attention, especially in the field of neoplastic vascularization.

\section{Angiogenesis in cancer}

Tumor growth and metastasis depend on angiogenesis and lymphangiogenesis triggered by chemical signals from tumor cells in a phase of rapid growth (Folkman 1971). In a previous study, Muthukkaruppan and colleagues (1982) compared the behavior of cancer cells infused into different regions of the same organ. One region was the iris with blood circulation; another was the anterior chamber without circulation. The cancer cells without blood circulation grew to $1-2 \mathrm{~mm}^{3}$ in diameter and then stopped, but grew beyond $2 \mathrm{~mm}^{3}$ when placed in an area where angiogenesis was possible. In the absence of vascular support, tumors may become necrotic or even apoptotic (Holmgren et al 1995; Parangi et al 1996). Therefore, angiogenesis is an important factor in the progression of cancer. Neovascularization, including tumor angiogenesis, is basically a four-step process. First, the basement membrane in tissues is injured locally. There is immediate destruction and hypoxia. Second, endothelial cells activated by angiogenic factors migrate. Third, endothelial cells proliferate and stabilize. Fourth, angiogenic factors continue to influence the angiogenic process. 
Vascular endothelial cells divide only about every 1000 days on average (Denekamp 1993). Angiogenesis is stimulated when tumor tissues require nutrients and oxygen. Angiogenesis is regulated by both activator and inhibitor molecules. However, up-regulation of the activity of angiogenic factors is itself not sufficient for angiogenesis of the neoplasm. Negative regulators or inhibitors of vessel growth need to also be down-regulated (Figure 1) (Dameron et al 1994).

\section{Endogenous angiogenic factors}

More than a dozen different proteins have been identified as angiogenic activators, including vascular endothelial growth factor (VEGF), basic fibroblast growth factor (bFGF), angiogenin, transforming growth factor (TGF)- $\alpha$, TGF- $\beta$, tumor necrosis factor (TNF)- $\alpha$, platelet-derived endothelial growth factor, granulocyte colony-stimulating factor, placental growth factor, interleukin-8, hepatocyte growth factor, and epidermal growth factor (Table 1). The VEGF family and their receptors (VEGFR) are receiving increasingly more attention in the field of neoplastic vascularization. VEGF is a powerful angiogenic agent in neoplastic tissues, as well as in normal tissues. Under the influence of certain cytokines and other growth factors, the VEGF family appears in cancerous tissue and the adjacent stroma, and plays an important role in neovascularization (Folkman 1990, 1995a, 1995b). Some angiogenic phenotypes can be triggered by hypoxia resulting from the increasing distance between the growing tumor cells and the capillaries or from the inefficiency of new vessels. Hypoxia induces the expression of VEGF and its receptor via hypoxia-inducible factor- $1 \alpha$ (HIF-1 $\alpha$ ) (Bottaro and Liotta 2003). Tumor cells feed on the new blood vessels by producing VEGF and then secreting it into the surrounding tissue. When the tumor cells encounter endothelial cells, they bind to receptors on the outer surface of the endothelial cell. The binding of VEGF to its receptor activates relay proteins that transmit a signal into the nucleus of the endothelial cell. The nuclear signal prompts a group of genes to make products needed for new endothelial cell growth.

Endothelial cells activated by VEGF produce matrix metalloproteinases (MMPs). The MMPs break down the extracellular matrix which fills the spaces between cells and is made of protein and polysaccharides. This matrix permits the migration of endothelial cells. The endothelial cells begin to divide as they migrate into the surrounding tissues. Soon they organize into hollow tubes that evolve gradually into a mature network of blood vessels with the help of an adhesion factor, such as integrin $\alpha$ or $\beta$ (Mizejewski 1999; Nelson et al 2000). Newly formed blood vessels need to stabilize or mature. Angiotensin-1, -2, and their receptor Tie-2 can stabilize and govern vascular growth (Suri et al 1996; Maisonpierre et al 1997; Tournaire et al 2004).

Among the VEGF family, VEGF-A, VEGF-B, VEGF$C$ and VEGF-E acting on their respective receptors cause proliferation of blood vessels, while VEGF-C and VEGF$\mathrm{D}$ are involved in lymphangiogenesis (Neufeld et al 1999; Mandriota et al 2001; Rafii and Skobe 2003). Vascular endothelial growth factor-A is also known as VEGF/vascular permeability factor (VPF) (Leung et al 1989). The human VEGF-A gene has been mapped to 6q21.3 (Vincenti et al 1996). Vascular endothelial growth factor-A is a heparinbinding glycoprotein that occurs in at least six molecular isoforms, which consist of 121, 145, 165, 183, 189, and 206 amino acids and are the result of alternative splicing of the mRNA (Ferrara et al 1992; Ferrara 1996; Stalmans et al 2002). VEGF-A is a potent and very specific mitogen for vascular endothelial cells and stimulates the full cascade of events required for angiogenesis (Leung et al 1989; Conn et al 1990), and is overexpressed in a variety of tumors (Dvorak 2002). VEGF-B exists as two protein isoforms, VEGF-B167 and VEGF-B186, resulting from different

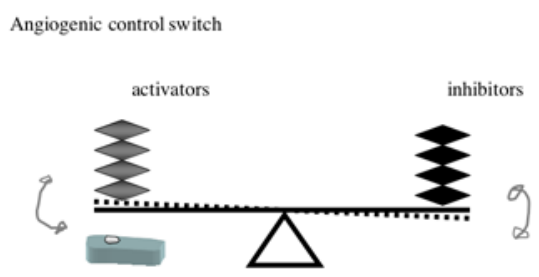

a) "SWITCH OFF"

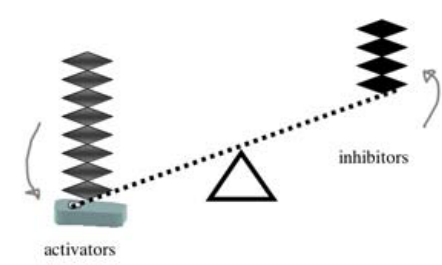

b) "SWITCH ON"

Figure I Angiogenesis is regulated by a balance between activators and inhibitors (a). When tumor tissues require fuel (nutrients and oxygen), angiogenesis is stimulated. However, up-regulation of by the activity of angiogenic activators alone is not sufficient for angiogenesis of the neoplasm. Negative regulators or inhibitors of vessel growth need also to be down-regulated (b). 
Table I Endogenous regulators of angiogenesis

\begin{tabular}{|c|c|}
\hline Activators & Inhibitors \\
\hline \multicolumn{2}{|l|}{ Growth factors } \\
\hline \multicolumn{2}{|c|}{ Vascular endothelial growth factor family } \\
\hline \multicolumn{2}{|c|}{ Acidic and basic fibroblast growth factor } \\
\hline \multicolumn{2}{|c|}{ Angiogenin } \\
\hline \multicolumn{2}{|l|}{ Angiostatin } \\
\hline \multicolumn{2}{|l|}{ Transforming growth factor } \\
\hline \multicolumn{2}{|l|}{ Tumor necrosis factor- $\alpha$} \\
\hline \multicolumn{2}{|c|}{ Plated-delivered endothelial growth factor } \\
\hline \multicolumn{2}{|l|}{ Hepatocyte growth factor } \\
\hline \multicolumn{2}{|l|}{ Epidermal growth factor } \\
\hline \multicolumn{2}{|l|}{ Placental growth factor } \\
\hline \multicolumn{2}{|c|}{ Granulocyto colony stimulating factor } \\
\hline \multicolumn{2}{|l|}{ Cytokines } \\
\hline \multicolumn{2}{|l|}{ Interleukin-I } \\
\hline Interleukin-6 & Interleukin-10 \\
\hline Interleukin-8 & Interleukin-12 \\
\hline \multicolumn{2}{|l|}{ Proteases and protease inhibitors } \\
\hline Cathepsin & $\begin{array}{l}\text { Tissue inhibitor } \\
\text { metalloprotease }\end{array}$ \\
\hline Gelatinase A, B & $\begin{array}{l}\text { Prasminogen } \\
\text { activator-inhibitor-I }\end{array}$ \\
\hline \multicolumn{2}{|l|}{ Stromelysin } \\
\hline \multicolumn{2}{|c|}{ Urokinase-type plasminogen activator } \\
\hline \multicolumn{2}{|l|}{ Trace elements } \\
\hline Copper & Zinc \\
\hline \multicolumn{2}{|l|}{ Oncogenes } \\
\hline $\begin{array}{l}\text { c-myc ras } \\
\text { c-src v-raf } \\
\text { c-jun }\end{array}$ & $\mathrm{p} 53 \mathrm{Rb}$ \\
\hline \multicolumn{2}{|l|}{ Endogenous modulators } \\
\hline Alpha 5 Beta 3 integrin & Angiopoietin-2 \\
\hline Angiopoitin-I & Angiotensin \\
\hline Angiostatin II (ATI receptor) & $\begin{array}{l}\text { Angiostatin II (AT2 } \\
\text { receptor) }\end{array}$ \\
\hline Endothelin & Caveolin-I, -2 \\
\hline Erythropoietin & Endostatin \\
\hline Hypoxia & Interferon-alpha \\
\hline Nitric oxide synthase & Isoflsvones \\
\hline \multicolumn{2}{|c|}{ Plated-activating factor Platerat factor 4} \\
\hline \multicolumn{2}{|l|}{ Prostaglandin $\mathrm{E}$} \\
\hline Prolactin (16 kd fragment) & \\
\hline
\end{tabular}

Abbreviations: ATI, angiotensin-I; AT2, angiotensin-2.

spliced mRNA and binds specifically to VEGFR-1. However, VEGF-B forms a heterodimer with VEGF-A (Olofsson et al 1996), which may alter its interaction with its biological receptors and modify its normal physiological effects. While VEGF-B is widely expressed in heart, skeletal muscle, and vascular cells (Olofsson et al 1996; Yonekura et al 1999), its biological function remains unclear. It has also been reported that VEGF-B levels increase both throughout development and after birth, closely correlating with the progression of cardiac angiogenesis (Bellomo et al
2000). VEGF-C has a mature form that consists of a VEGF homology domain, which contains receptor-binding sites and is 30\% identical in amino-acid sequence of VEGF165 (Joukov et al 1998). Unlike VEGF-A, the expression of VEGF-C does not appear to be regulated by hypoxia (Enholm et al 1997). The expression of VEGF-C appears to be restricted to early development and certain pathological settings such as tumor angiogenesis and lymphangiogenesis (Peeper 2001). VEGF-D is known as c-FOS-induced growth factor (FIGF), and the mature form has $61 \%$ identical aminoacid sequence with VEGF-C, and both of these growth factors bind to the same receptors on human endothelial cells, namely VEGFR-2 and -3 (Orlandini et al 1996; Achen et al 1998; Baldwin et al 2001). VEGF-C and VEGF-D bind and activate VEGFR-3, regulating lymphangiogenesis as well as angiogenesis in the mid-stages of embryogenesis (Migdal et al 1998; Soker et al 1998). VEGF-E is encoded by the parapoxvirus or Orf virus (Lyttle et al 1994). The interaction of VEGF-E with its receptor seems to promote endothelial cell growth (Ogawa et al 1998). There is a significant overlap between the binding pocket of VEGF-A and VEGF-E on VEGFR-2 which may suggest alliance of the two molecules in final response or alternatively an antagonistic relationship between these two factors (Kiba et al 2003).

\section{Inhibitors of angiogenesis}

Up-regulation of the activity of angiogenic factors is in itself not enough to initiate blood vessel growth, and the functions of negative regulators or inhibitors of vessel growth may need to be down-regulated. There are many naturally occurring proteins that can inhibit angiogenesis, including angiostatin, endostatin, interferon, platelet factor 4, thorombospondin, prolactin $16 \mathrm{kd}$ fragment, and tissue inhibitor of metalloproteinase-1, -2, and -3 (Table 1). Angiostatin is composed of one or more fragments of plasminogen (Stack et al 1999). It induces apoptosis in endothelial cells and tumor cells, and inhibits migration and the formation of tubules in endothelial cells (Claesson-Welch et al 1998; Lucas et al 1998). Immunohistochemical examination of angiostatin-treated tumors indicated a decrease in the expression of mRNA for VEGF and bFGF (Kirsch et al 1998). Endostatin is a $20 \mathrm{kDa}$ C-terminal fragment of type XVIII collagen (O'Reilly et al 1997), a component of the basement membrane. It binds to the $\alpha 5 \beta 1 /$ $\alpha v \beta 3$ integrin, the major fibronectin receptor in endothelial cells (Rehn et al 2001; Wickstrom et al 2002) and may block endothelial cell focal adhesions (Wickstrom et al 2002). 
Endostatin also inhibits the growth factor (eg, bFGF and VEGF-A), and induces proliferation and migration of endothelial cells in vitro and in vivo (O’Reilly et al 1997; Dhanabal et al 1999; Olsson et al 2004).

\section{Angiogenesis and the prognosis of cancer}

Several studies have indicated that angiogenic activators play an important part in the growth and spread of tumors. On immunohistochemical examination, the VEGF family and their receptors were found to be expressed in about half of the human cancers investigated (Salven et al 1998). These factors are known to affect the prognosis of adenocarcinomas that have developed in the uterine cervix, (Hashimoto et al 2001), endometrium, (Hirai et al 2001), ovary (Boocock et al 1995; Yokoyama et al 2003; Nishida et al 2004), and stomach (Yonemura et al 1999; Amioka et al 2002). In addition, a significant correlation between the expression of VEGF and prognosis has been described in colorectal cancer (Andre et al 2000; George et al 2001; Furudoi et al 2002), breast cancer (Kurebayashi et al 1999; Gunningham et al 2000; Kinoshita et al 2001; Skobe et al 2001), lung cancer (Decaussin et al 1999; Niki et al 2000; Kajita et al 2001), head and neck squamous cell carcinoma (O-charoenrat et al 2001), Kaposi sarcoma (Jussila et al 1998), and malignant mesothelioma (Ohta et al 1999). These studies also indicated that the levels of angiogenic factors in tissue reflect the aggressiveness with which tumor cells spread, and thus have predictive value in the identification of the high-risk patients with poor prognosis.

Neovascularization reduces a tumor's accessibility to chemotherapeutic drugs. Increased interstitial pressure from leaky vessels in the tumor, in the relative absence of intratumoral lymphatic vessels, causes vascular compression and central necrosis (Folkman 1995b). So it is not surprising that the prognostic value of neoplastic angiogenic factors is controversial. Work carried out in our laboratory using immunohistochemistry to examine the expression of the VEGF family and their receptors in 80 cases of ovarian carcinoma, revealed the presence of VEGF-A, VEGF-C, VEGFR-2, and VEGFR-3 in the cytoplasm of tumor cells, and also of endothelial cells of the blood and lymph vessels in the stroma adjacent to tumor nests (Nishida et al 2004). The tissue levels of VEGF-C and VEGFR-2 significantly correlated with the progression and prognosis of the cancer, while there was no significant relationship between the expression of
VEGF-A and VEGFR-3 cancerous cell pathology (Nishida et al 2004).

\section{Antiangiogenic treatment of cancer}

For some localized solid malignant tumors, surgery has curative potential, but the use of radiation and cytotoxic chemotherapy is a more appropriate route of treatment for surgically unresectable tumors (Kim et al 2002; Long 2003; Brenner et al 2004; Pfister et al 2004; Lin and Beerm 2004; Awada and de Castro 2005; Evans 2005; Goldberg 2005). Despite advances in both therapeutic modalities, treatment results are disappointing in patients with advanced disease (Jemal et al 2005). A new therapeutic strategy is urgently required.

Angiogenesis is regulated by both activator and inhibitor molecules. The switch to the angiogenic phenotype involves a change in the local equilibrium between positive and negative regulators of angiogenesis. This signaling activates certain genes in the host tissue that make proteins which encourage the growth of blood vessels (Majima et al 2000; Semenza 2002). Cancer cells require access to blood vessels for growth and metastasis. The discovery of angiogenic inhibitors provides hope for reducing the mortality and morbidity from carcinomas. Five classes of angiogenic antagonists are currently in clinical trials: inhibitors of proteases (inhibit the synthesis of MMP); endothelial cell migration and proliferation; angiogenic growth factors; matrix proteins on the endothelial cell surface such as integrins, copper; and inhibitors with unique mechanisms. There has been a modest positive outcome with the use of antiangiogenic drugs based on some clinical trials (Cobleigh et al 2003; Yang et al 2003), but no long-term survival benefits have been documented as yet (Mayer 2004). However, when used in combination with chemotherapy or radiation therapy, these drugs tend to increase survival (Hurwiz et al 2004). Evidence seems to support the view that cytotoxic agents and antiangiogenic agents would destroy both cancer cells and endothelial cells (Teicher 1996). Cytotoxic therapy suppresses cancer directly and angiogenic therapy suppresses it indirectly by depriving cells of nutrients and oxygen (Rakesh 2005). The use of angiogenesis-suppressors and receptor-inhibitors can prohibit the neovascularization of cancer tissue as well as growth of the tumor, and thus might be beneficial to the treatment of cancer. Paradoxically, some studies have shown that antiangiogenic agents as well as radiation can compromise the delivery of drugs to tumors (Ma et al 2001). 
The new vasculature is structurally and functionally abnormal (Jain 2004), and the blood vessels are immature and leaky (Tong et al 2004). Unlike normal blood vessels: 1) tumor vessels have no or a detached pericyte and basement membrane (Inai et al 2004; Tong et al 2004; Winkler et al 2004); 2) the diameter of the vessel is smaller (Yuan et al 1996; Izumi et al 2002; Tong et al 2004; Winkler et al 2004); 3) the vascular density is heterogeneous (Izumi et al 2002; Tong et al 2004; Winkler et al 2004); 4) permeability to large molecules is high (Yuan et al 1996; Tong et al 2004; Willett et al 2004; Winkler et al 2004); and 5) the pressure of microvascular and interstitial fluid is almost the same (Lee et al 2000; Tong et al 2004; Willet et al 2004). These abnormalities contribute to heterogeneity in tumor blood flow. In addition, the pressure generated by proliferating cancer cells compresses intratumoral blood and lymphatic vessels and leads to an abnormal microenvironment characterized by an impaired blood supply, interstitial hypertension, hypoxia, and acidosis (Padera et al 2004). It is possible that these factors interfere with the delivery of therapeutic drugs, rendering tumor cells resistant to both radiation and some forms of cytotoxic therapy, induce genetic stability and select for more malignant cells with increased metastatic potential, and compromise the cytotoxic functions of immune cells. Hence, Rakesh (2005) emphasizes that the tumor vasculature should be normalized. Some trials based on normalization of tumor vasculature have started, however, data are not currently available. There is a report that normalization can be achieved by controlling the dose of an already existing medicine, for example, low-dose anti-VEGF treatment. In the meantime, cancerous tissue is composed of the neoplastic cells themselves and the supporting stroma.

\section{References}

Achen MG, Jeltsch M, Kukk E, et al. 1998. Vascular endothelial growth factor D (VEGF-D) is a ligand for the tyrosine kinases VEGF receptor 2 (Flk1) and VEGF receptor 3 (Flt4). Proc Natl Acad Sci U S A, 95:54853.

Amioka T, Kitadai Y, Tanaka S, et al. 2002. Vascular endothelial growth factor-C expression predicts lymph node metastasis of human gastric carcinomas invading the submucosa. Eur J Cancer, 38:1413-19.

Andre T, Kotelevets L, Vaillant JC, et al. 2000. Vegf, Vegf-B, Vegf-C and their receptors KDR, FLT-1 and FLT-4 during the neoplastic progression of human colonic mucosa. Int J Cancer, 86:174-81.

Awada A, de Castro G Jr. 2005. An integrated approach for tailored treatment in breast cancer. Ann Oncol, 16:203-8

Baldwin ME, Catimel B, Nice EC, et al. 2001. The specificity of receptor binding by vascular endothelial growth factor- $\mathrm{D}$ is different in mouse and man. J Biol Chem, 276:19166-71.
Bellomo D, Headrick JP, Silins GU, et al. 2000. Mice lacking the vascular endothelial growth factor-B gene (Vegfb) have smaller hearts, dysfunctional coronary vasculature, and impaired recovery from cardiac ischemia. Circ Res, 86:29-35

Bottaro DP, Liotta LA. 2003. Cancer: Out of air is not out of action. Nature, 423:593-5.

Boehm T, Folkman J, Browder T, et al. 1997. Antiangiogenic therapy of experimental cancer does not induce acquired drug resistance. Nature, 390:404-7.

Boocock CA, Charnock-Jones DS, Sharkey AM, et al. 1995. Expression of vascular endothelial growth factor and its receptors flt and KDR in ovarian carcinoma. J Natl Cancer Inst, 87:506-16.

Brenner B, Ilson DH, Minsky BD. 2004. Treatment of localized esophageal cancer. Semin Oncol, 31:554-65.

Claesson-Welsh L, Welsh M, Ito N et al. 1998. Angiostatin inducesendothelial cells apoptosis and activation of focal adhesion kinase independently of the integrin-binding motif RGD. Proc Natl Acad Sci U S A, 95:5579-83.

Cobleigh MA, Langmuir VK, Sledge GW, et al. 2003. A phase I/II doseescalation trial of bevacizumab in previously treated metastatic breast cancer. Semin Oncol, 30:117-24.

Conn G, Bayne ML, Soderman DD, et al. 1990. Amino acid and cDNA sequence of a vascular endothelial cell mitogen that is homologous to platelet-derived growth factor. Proc Natl Acad Sci U S A, 87:262832.

Dameron KM, Volpert OV, Tainsky MA, et al.1994. Control of angiogenesis in fibroblasts by p53 regulation of thorombospongin-1. Science, 265:1582-4.

Decaussin M, Sartelet H, Robert C, et al. 1999. Expression of vascular endothelial growth factor (VEGF) and its two receptors (VEGF-R1Flt1 and VEGF-R2-Flk1/KDR) in non-small cell lung carcinomas (NSCLCs): Correlation with angiogenesis and survival. J Pathol, 188:369-77.

Denekamp J. 1993. Angiogenesis, neovascular proliferation and vascular pathophysiology as targets for cancer therapy. Br J Radiol, 66:18196.

Dhanabal M, Ramchandran R, Volk R, et al. 1999. Endostatin: yeast production, mutants, and antitumor effecting renal cell carcinoma. Cancer Res, 59:189-97.

Dvorak HF. 2002. Vascular permeability factor/vascular endothelial growth factor: a critical cytokine in tumor angiogenesis and a potential target for diagnosis and therapy. J Clinl Oncol, 20:4368-80

Enholm B. Paavonen K, Ristimaki A, et al. 1997. Comparison of VEGF, VEGF-B, VEGF-C and Ang-1 mRNA regulation by serum, growth factors, oncoproteins and hypoxia. Oncogene, 14:2475-83.

Evans DB. 2005. Preoperative chemoradiation for pancreatic cancer. Semin Oncol, 32:25-9.

Ferrara N, Jakeman L, Houck K, et al. 1992. Molecular and biological properties of the vascular endothelial growth factor family of proteins. Endocr Rev, 13:18-32.

Ferrara N. 1996. Vascular endothelial growth factor. Eur J Cancer, 32:2413-22.

Folkman J. 1971. Tumor angiogenesis theraperutic implications. $N$ Engl J Med, 285:1182-6.

Folkman J. 1990. What is the evidence that tumors are angiogenesis dependent? J Natl Cancer Inst, 82:4-6.

Folkman J. 1995a. Angiogenesis in cancer, vascular, rheumatoid and other disease. Nat Med, 1:27-31.

Folkman J. 1995b. Seminars in medicine of the Beth Israel Hospital, Boston. Clinical applications of research on angiogenesis. $N$ Engl $J$ Med, 333:1757-63.

Furudoi A, Tanaka S, Haruma K, et al. 2002. Clinical significance of vascular endothelial growth factor $\mathrm{C}$ expression and angiogenesis at the deepest invasive site of advanced colorectal carcinoma. Oncology, 62:157-66.

George ML, Tutton MG, Janssen F, et al. 2001. VEGF-A, VEGF-C, and VEGF-D in colorectal cancer progression. Neoplasia, 3:420-7. 
Goldberg RM. 2005. Advances in the treatment of metastatic colorectal cancer. Oncologist, 10(Suppl 3):40-8.

Gunningham SP, Currie MJ, Han C, et al. 2000. The short form of the alternatively spliced flt-4 but not its ligand vascular endothelial growth factor $\mathrm{C}$ is related to lymph node metastasis in human breast cancers. Clin Cancer Res, 6:4278-86.

Hashimoto I, Kodama J, Seki N, et al. 2001. Vascular endothelial growth factor-C expression and its relationship to pelvic lymph node status in invasive cervical cancer. Br J Cancer, 85:93-7.

Hirai M, Nakagawara A, Oosaki T, et al. 2001. Expression of vascular endothelial growth factors (VEGF-A/VEGF-1 and VEGF-C/VEGF2) in postmenopausal uterine endometrial carcinoma. Gynecol Oncol, 80:181-8.

Holmgren L, O’Reilly MS, Folkman J. 1995. Dormancy of micrometastases: balance proliferation and apoptosis in the presence of angiogenesis suppression. Nat Med, 1:149-53.

Hurwitz H, Fehrenbacher L, Novotny W, et al. 2004. Bevacizumab plus Irinotecan, Fluorouracil, and Leucovorin for Metastatic Colorectal Cancer. N Eng J Med, 350:2335-42

Inai T, Mancuso M, Hashizume H, et al. 2004. Inhibition of vascular endothelial growth factor (VEGF) signaling in cancer causes loss of endothelial fenestrations, regression of tumor vessels, and appearance of basement membrane ghosts. Am J Pathol, 165:35-52.

Izumi Y, Xu L, di Tomaso E, et al. 2002. Tumour biology: herceptin acts as an anti-angiogenic cocktail. Nature, 416:279-80

Jain RK. 2004. Vascular and interstitial biology of tumors. In: Abeloff M, (ed). Clinical oncology, 3rd ed. Philadelphia: Elsevier, p 153-72.

Jemal A, Murray T, Ward E, et al. 2005. Cancer statistics. CA Cancer J Clin, 55:10-30.

Joukov V, Kumar V, Sorsa T, et al. 1998. A recombinant mutant vascular endothelial growth factor-C that has lost vascular endothelial growth factor receptor-2 binding, activation, and vascular permeability activities. J Biol Chem, 20:6599-602.

Jussila L, Valtola R, Partanen TA, et al. 1998. Lymphatic endothelium and Kaposi sarcoma spindle cells detected by antibodies against the vascular endothelial growth factor receptor-3. Cancer Res, 58:1599604.

Kajita T, Ohta Y, Kimura K, et al. 2001. The expression of vascular endothelial growth factor $\mathrm{C}$ and its receptors in non-small cell lung cancer. Br J Cancer, 85:255-60.

Kirsch M, Strasser J, Allende R, et al. 1998. Angiogenesis suppresses malignant glioma growth in vivo. Cancer Res, 58:4654-9.

Kiba A, Sagara H, Hara T, et al. 2003. VEGFR-2-specific ligand VEGF-E induces non-edematous hyper-vascularization in mice. Biochem Biophys Res Commun, 301:371-7

Kim RY, Omura GA, Alvarez RD. 2002.Advances in the treatment of gynecologic malignancies. Part 2: Cancers of the uterine corpus and ovary. Oncology, 16:1669-80.

Kinoshita J, Kitamura K, Kabashima A, et al. 2001. Clinical significance of vascular endothelial growth factor-C (VEGF-C) in breast cancer. Breast Cancer Res Treat, 66:159-64.

Kurebayashi J, Otsuki T, Kunisue H, et al. 1999. Expression of vascular endothelial growth factor (VEGF) family members in breast cancer. Jpn J Cancer Res, 90:977-81.

Lee CG, Heijn M, di Tomaso E, et al. 2000. Anti-Vascular endothelial growth factor treatment augments tumor radiation response under normoxic or hypoxic conditions. Cancer Res, 60:5565-70.

Leung DW, Cachianes G, Kuang WJ, et al. 1989. Vascular endothelial growth factor is a secreted angiogenic mitogen. Science, 246:13069.

Lin J, Beerm DG. 2004. Molecular biology of upper gastrointestinal malignancies. Semin Oncol, 31:476-86.

Long HJ 3rd. 2003. Current research directions for locally advanced cervix cancer. Curr Oncol Rep, 5:468-72.

Lucas R, Holmgren L, Garcia I, et al. 1998. Multiple forms of angiostatin induce apoptosis in endothelial cells. Blood, 92:4730-41.
Lyttle DJ, Fraser KM, Fleming SB, et al. 1994. Homologs of vascular endothelial growth factor are encoded by the poxvirus orf virus. $J$ Virol, 68:84-92.

Ma J, Pulfer S, Li S, et al. 2001. Pharmacodynamic-mediated reduction of temozolomide tumor concentrations by the angiogenesis inhibitor TNP-470. Cancer Res, 61:5491-8.

Maisonpierre PC, Suri C, Jones PF, et al. 1997. Angiopoietin-2, a natural antagonist for Tie2 that disrupts in vivo angiogenesis. Science, 277:5560.

Majima M, Hayashi I, Muramatsu M, et al. 2000. Cyclo-oxygenase-2 enhances basic fibrobrast growth factor-induced angiogenesis through induction o vascular endothelial growth factor in rat sponge implants. Br J Pharmacol, 268:641-9

Mandriota SJ, Jussila L, Jeltsch M, et al. 2001. Vascular endothelial growth factor-C-mediated lymphangiogenesis promotes tumour metastasis. EMBO J, 20:672-82.

Mayer RJ. 2004. Two steps forward in the treatment of colorectal cancer. N Engl J Med, 350:2406-8.

Migdal M, Huppertz B, Tessler S, et al. 1998. Neuropilin-1 is a placenta growth factor-2 receptor. J Biol Chem, 273:22272-8.

Mizejewski GJ. 1999. Role of integrins in cancer: survey of expression patterns. Proc Soc Exp Biol Med, 222:124-38.

Muthukkaruppan VR, Kubai L, Auerbach R. 1982. Tumor-induced neovascularization in the mouse eye. J Natl Cancer Inst, 69:699-708.

Nelson AR, Fingleton B, Rothenberg ML, et al. 2000. Matrix metalloproteinases: biologic activity and clinical implications. J Clin Oncol, 18:1135-49.

Neufeld G, Cohen T, Gengrinovitch S, et al. 1999. Vascular endothelial growth factor (VEGF) and its receptors. FASEB J, 13:9-22.

Niki T, Iba S, Tokunou M, et al. 2000. Expression of vascular endothelial growth factor A, B, C, and D and their relationships to lymph node status in lung adenocarcinoma. Clin Cancer Res, 6:2431-9.

Nishida N, Yano H, Komai K, et al. 2004. Vascular endothelial growth factor $\mathrm{C}$ and vascular endothelial growth factor receptor 2 are related closely to the prognosis of ovarian carcinoma. Cancer, 101:1364-74.

O-charoenrat P, Rhys-Evans P, Eccles SA. 2001. Expression of vascular endothelial growth factor family members in head and neck squamous cell carcinoma correlates with lymph node metastasis. Cancer, 92:55668.

Ogawa S, Oku A, Sawano A, et al. 1998. A novel type of vascular endothelial growth factor, VEGF-E (NZ-7 VEGF), preferentially utilizes KDR/Flk-1 receptor and carries a potent mitotic activity without heparin-binding domain. J Biol Chem, 273:31273-82.

Ohta Y, Shridhar V, Bright RK, et al. 1999. VEGF and VEGF type C play an important role in angiogenesis and lymphangiogenesis in human malignant mesothelioma tumours. Br J Cancer, 81:54-61.

Olsson AK, Johansson I, Åkerud H, et al. 2004. The minimal active domain of endostatin is a heparin-binding motif that mediates inhibition of tumor vascularization. Cancer Res, 64:9012-17.

Olofsson B, Pajusola K, Kaipainen A, et al. 1996. Vascular endothelial growth factor B, a novel growth factor for endothelial cells. Proc Natl Acad Sci U S A, 93:2576-81.

O’Reilly MS, Boehm T, Shing Y, et al.1997. Endostatin: an endogenous inhibitor of angiogenesis and tumor growth. Cell, 88:277-85.

Orlandini M, Marconcini L, Ferruzzi R et al. 1996. Identification of a cfos- induced gene that is related to the platelet-derived growth factor/ vascular endothelial factor family. Proc Natl Acad Sci U S A, 93:1167580.

Padera TP, Stoll BR, Tooredman JB, et al. 2004. Pathology: cancer cells compress intratumour vessels. Nature, 427:695.

Pfister DG, Johnson DH, Azzoli CG, et al. 2004. American Society of Clinical Oncology treatment of unresectable non-small-cell lung cancer guideline: updated 2003. J Clin Oncol, 22:330-53.

Parangi S, O’Reilly M, Christofori G, et al. 1996. Angiogenesis therapy of transgenic mice impairs de novo tumor growth. Proc Natl Acad Sci U S A, 93:2002-7. 
Peeper MS. 2001. Lymphangiogensis and tumor metastasis: Myth or reality? Clin Cancer Res, 7:462-8.

Rakesh KJ. 2005. Normalization of tumor vasculature: an emerging concept in antiangiogenic therapy. Science, 307:58-62.

Rafii S, Skobe M. 2003. Spilitting vessels: Keeping lymph apart from blood. Nature Med, 9:166-8.

Rehn M, Veikkola T, Kukk-Valdre E, et al. 2001. Interaction of endostatin with integrins implicated in angiogenesis. Proc Natl Acad Sci U S A, 98:1024-9.

Salven P, Lymboussaki A, Heikkila P, et al. 1998. Vascular endothelial growth factors VEGF-B and VEGF-C are expressed in human tumors. Am J Pathol, 153:103-8.

Semenza G. 2002. Signal transduction to hypoxia-inducible factor 1. Biochem Pharmacol, 64:993-8.

Skobe M, Hawighorst T, Jackson DG, et al. 2001. Induction of tumor lymphangiogenesis by VEGF-C promotes breast cancer metastasis. Nat Med, 7:192-8.

Soker S, Takashima S, Miao HQ, et al. 1998. Neuropilin-1 is expressed by endothelial and tumor cells as an isoform-specific receptor for vascular endothelial growth factor. Cell, 92:735-45.

Stack MS, Gately S, Bafetti LM, et al. 1999. Angiostatin inhibits endothelial and melanoma cellular invasion by blocking matrixenhanced plasminogen activation. Biochem J, 340:77-84.

Stalmans I, Ng YS, Rohan R, et al. 2002. Arteriolar and venular patterning in retinas of mice selectively expressing VEGF isoforms. J Clin Invest, 109:327-36.

Suri C, Jones PF, Patan S, et al. 1996. Requisite role of angiopoietin-1, a ligand for the TIE2 receptor, during embryonic angiogenesis. Cell, 87:1171-80.

Teicher BA. 1996. A systems approach to cancer therapy. (Antioncogenics + standard cytotoxics->mechanism(s) of interaction). Cancer Metastasis Rev, 15:247-72.

Tong RT, Boucher Y, Kozin SV, et al. 2004. Vascular normalization by vascular endothelial growth factor receptor 2 blockade induces a pressure gradient across the vasculature and improves drug penetration in tumors. Cancer Res, 64:3731-6.
Tournaire R, Simon MP, le Noble F, et al. 2004. A short synthetic peptide inhibits signal transduction, migration and angiogenesis mediated by Tie2 receptor. EMBO Rep, 5:262-7.

Vincenti V, Cassano C, Rocchi M, et al. 1996. Assignment of the vascular endothelial growth factor gene to the human chromosome 6q21.3. Circulation, 93:1493-5.

Wickstrom SA, Alitalo K, Keski-Oja J. 2002. Endostatin associates with integrin alfa5beta1 and caveolin-1, and activates Src via a tyrosyl phosphatasa-dependent pathway in human endothelial cells. Cancer Res, 62:5580-9.

Willett CG, Boucher Y, di Tomaso E, et al. 2004. Direct evidence that the VEGF-specific antibody bevacizumab has antivascular effects in human rectal cancer. Nat Med, 10:145-7.

Winkler F, Kozin SV, Tong RT, et al. 2004. Kinetics of vascular normalization by VEGFR2 blockade governs brain tumor response to radiation: role of oxygenation, angiopoietin-1, and matrix metalloproteinases. Cancer Cell, 6:553-63.

Yang JC, Haworth L, Sherry RM, et al. 2003. A randomized trial of bevacizumab, an anti-vascular endothelial growth factor antibody, for metastatic renal cancer. $N$ Engl J Med, 349:427-34.

Yokoyama Y, Charnock-Jones DS, Licence D, et al. 2003. Vascular endothelial growth factor $\mathrm{D}$ is an independent prognostic factor on epithelial ovarian carcinoma. Br J Cancer, 88:237-44.

Yonekura H, Sakurai S, Liu X, et al. 1999. Placenta growth factor and vascular endothelial growth factor $\mathrm{B}$ and $\mathrm{C}$ expression in microvascular endothelial cells and pericytes: implication in autocrine and paracrine regulation of angiogenesis. J Biol Chem, 274:35172-8

Yonemura Y, Endo Y, Fujita H, et al. 1999. Role of vascular endothelial growth factor $\mathrm{C}$ expression in the development of lymph node metastasis in gastric cancer. Clin Cancer Res, 5:1823-9.

Yuan F, Chen Y, Dellian M,et al. 1996. Time-dependent vascular regression and permeability changes in established human tumor xenografts induced by an anti-vascular endothelial growth factor/vascular permeability factor antibody. Proc Natl Acad Sci U S A, 93:1476570 . 
